\title{
Identification and characterization of two novel mutations in the $L P L$ gene causing type I hyperlipoproteinemia
}

\author{
Piero Pingitore, PhD, Saverio Massimo Lepore, PhD, Carlo Pirazzi, MD, PhD, \\ Rosellina Margherita Mancina, PhD, Benedetta Maria Motta, PhD, Luca Valenti, MD, \\ Knut Erik Berge, MD, PhD, Kjetil Retterstøl, MD, PhD, Trond P. Leren, MD, PhD, \\ Olov Wiklund, MD, $\mathrm{PhD}^{1}$, Stefano Romeo, MD, PhD*,1
}

Department of Molecular and Clinical Medicine, University of Gothenburg, Gothenburg, Sweden (Drs Pingitore, Pirazzi, Mancina, Motta, Wiklund, and Romeo); Clinical Nutrition Unit, Department of Medical and Surgical Sciences, Magna Graecia University, Catanzaro, Italy (Drs Lepore and Romeo); Cardiology Department, Sahlgrenska University Hospital, Gothenburg, Sweden (Drs Pirazzi, Wiklund, and Romeo); Internal Medicine, Fondazione IRCCS Ca' Granda Ospedale Policlinico Milano, Milan, Italy (Dr Valenti); Department of Pathophysiology and Transplantation, Università degli Studi di Milano, Milan, Italy (Dr Valenti); Unit for Cardiac and Cardiovascular Genetics, Department of Medical Genetics, Oslo University Hospital, Ullevaal, Oslo, Norway (Drs Berge and Leren); Department of Nutrition, Institute for Basic Medical Sciences, University of Oslo, Oslo, Norway (Dr Retterstøl); and Lipid Clinic, Oslo University Hospital,

Rikshospitalet, Oslo, Norway (Dr Retterstøl)

\section{KEYWORDS:}

Type 1

hyperlipoproteinemia;

Hypertriglyceridemia;

Missense and frameshift mutations;

Familial lipoprotein lipase
BACKGROUND: Type 1 hyperlipoproteinemia is a rare autosomal recessive disorder most often caused by mutations in the lipoprotein lipase $(L P L)$ gene resulting in severe hypertriglyceridemia and pancreatitis.

OBJECTIVES: The aim of this study was to identify novel mutations in the $L P L$ gene causing type 1 hyperlipoproteinemia and to understand the molecular mechanisms underlying the severe hypertriglyceridemia.

METHODS: Three patients presenting classical features of type 1 hyperlipoproteinemia were recruited for DNA sequencing of the $L P L$ gene. Pre-heparin and post-heparin plasma of patients
The work was supported by the Swedish Research Council [Vetenskapsrådet (VR), 254439006], the Swedish Heart-Lung Foundation [244439007], the Swedish federal government funding under the Agreement on Medical Training and Medical Research (ALF) [76290], the Novonordisk Foundation Grant for Excellence in Endocrinology [244439012], the Swedish Diabetes Foundation [DIA 2014-052] (S.R.), the Wilhelm and Martina Lundgren Science Fund (P.P., R.M.M, (B)M.M and S.R.), the NilssonEhle funds from the Fysiografiska Sällsk-apet in Lund (R.M.M.), from Ricerca Corrente Fondazione Ca' Granda IRCCS Policlinico of Milan, Associazione Malattie Metaboliche del Fegato ONLUS, and the Fondazione Policlinico-INGM Molecular Medicine grant 2014-2016, My First AIRC Grant project code 16888 (L V.), the co-financed grant from the European Commission, the European Social Fund, and Calabria Region (S.M.L.).

${ }^{1}$ Shared senior authorship.
* Corresponding author. Wallenberg Laboratory, Bruna Stråket 16, Department of Molecular and Clinical Medicine, University of Gothenburg, SE-413 45 Göteborg, Sweden.

E-mail address: stefano.romeo@wlab.gu.se

Submitted February 8, 2016. Accepted for publication February 28, 2016. 
deficiency (FLD); Hyperchylomicronemia were used for protein detection analysis and functional test. Furthermore, in vitro experiments were performed in HEK293 cells. Protein synthesis and secretion were analyzed in lysate and medium fraction, respectively, whereas medium fraction was used for functional assay.

RESULTS: We identified two novel mutations in the $L P L$ gene causing type 1 hyperlipoproteinemia: a two base pair deletion (c.765_766delAG) resulting in a frameshift at position 256 of the protein (p.G256TfsX26) and a nucleotide substitution (c.1211 $\mathrm{T}>\mathrm{G}$ ) resulting in a methionine to arginine substitution (p.M404 R). LPL protein and activity were not detected in pre-heparin or post-heparin plasma of the patient with p.G256TfsX26 mutation or in the medium of HEK293 cells overexpressing recombinant p.G256TfsX26 LPL. A relatively small amount of LPL p.M404 R was detected in both pre-heparin and post-heparin plasma and in the medium of the cells, whereas no LPL activity was detected.

CONCLUSIONS: We conclude that these two novel mutations cause type 1 hyperlipoproteinemia by inducing a loss or reduction in LPL secretion accompanied by a loss of LPL enzymatic activity. (C) 2016 National Lipid Association. Published by Elsevier Inc. This is an open access article under the CC BY-NC-ND license (http://creativecommons.org/licenses/by-nc-nd/4.0/).

\section{Introduction}

Lipoprotein lipase (LPL) is an enzyme belonging to a mammalian lipase family. Other members of this family are pancreatic lipase, hepatic lipase, gastric lipase, and endothelial lipase. ${ }^{1,2}$ The human $L P L$ gene spans about $30 \mathrm{~kb}$ on the short arm of chromosome 8 and consists of 10 exons coding for a protein of 475 amino acids. ${ }^{3}$ Active LPL is a noncovalent dimer with a catalytic triad consisting of three amino acids (Ser, Asp, and His). ${ }^{4}$

LPL is a 55-KDa secreted glycoprotein synthesized from several cell types, such as adipocytes, macrophages, and muscle cells. ${ }^{5}$ After secretion, the protein binds to the surface of capillaries through the interaction of its positively charged heparin-binding domains ${ }^{6}$ with negatively charged heparan sulfate proteoglycans expressed on the surface of endothelial cells. ${ }^{7,8}$

LPL is responsible for the intravascular hydrolysis of TG-rich lipoproteins (TG) such as chylomicrons and very low-density lipoproteins. ${ }^{9,10}$ It catalyzes a crucial step in the removal of TG from bloodstream generating free fatty acids for different tissues. ${ }^{10}$ For full enzymatic activity, LPL requires some important cofactors: (1) apolipoprotein C-II and apolipoprotein A-V that are LPL activators; (2) glycosylphosphatidylinositol-anchored high-density lipoprotein-binding protein 1 , which is involved in LPL binding and transport to the endothelial cell wall; and (3) lipase maturation factor 1 an important endoplasmic reticulum transmembrane protein, which promotes LPL homodimerization. ${ }^{9,11,12}$ Loss of function mutations in one of all these genes result in type I hyperlipoproteinemia. ${ }^{13,14}$

Type I hyperlipoproteinemia, also known as Familial lipoprotein lipase deficiency or Familial hyperchylomicronemia, is a rare autosomal recessive disorder of lipoprotein metabolism estimated to affect approximately one per million individuals. In some ethnic groups, the frequency of this disorder is several fold higher (i.e., French Canadians, Afrikaner). ${ }^{15,16}$ Type I hyperlipoproteinemia is characterized by extremely high levels of triglycerides in the plasma ( $>880 \mathrm{mg} / \mathrm{dL}$ or $10 \mathrm{mmol} / \mathrm{L}$ ) due to a massive accumulation of chylomicrons due to impaired hydrolysis. ${ }^{17,18}$ Clinical features are recurrent episodes of abdominal pain and pancreatitis, as well as hepatosplenomegaly, eruptive cutaneous xanthomas, and lipemia retinalis. ${ }^{19}$

The main therapeutical approach of Type I hyperlipoproteinemia is based on diet treatment to reduce triglyceride (TG) levels. ${ }^{20}$ TG-lowering drugs, such as niacin and fibrates, are not effective in patients with type I hyperlipoproteinemia. ${ }^{21}$ Orlistat, a gastric lipase inhibitor that reduces fat availability, has been used successfully in the treatment of moderate and severe LPL deficiency. ${ }^{22,23}$ Recently, gene replacement using alipogene tiparvovec has been the very first therapy approved by European Medicines Agency for the treatment of type I hyperlipoproteinemia. ${ }^{24}$ Alipogene tiparvovec introduces a human $L P L$ gene into the body, resulting in the production of functional LPL. ${ }^{25}$ However, this gene therapy is indicated only in adults with genetic diagnosis of LPL deficiency who have had recurrent pancreatitis and with a residual lipoprotein mass in the circulation. ${ }^{24,26}$ Thus, careful genetic screening and functional testing of LPL are required to identify patients eligible for this new therapeutic approach.

In this article, we report two novel mutations in $L P L$ gene in three patients with severe hypertriglyceridemia and recurrent pancreatitis and show by in vitro experiments using HEK293 cells and blood samples that these genetic mutations result in different protein production and/or secretion and in both the cases, in a nonfunctional LPL protein.

\section{Materials and methods}

\section{Subjects}

A total of three individuals were selected among $(\mathrm{n}=85)$ referrals to the Lipid Clinic at Sahlgrenska University Hospital in Gothenburg (Sweden), between the first of April 2014 to the first of May 2015. Two individuals (patients 1 and 2) belonged to the same family. All three individuals were diagnosed with hypertriglyceridemia 
during hospitalization for the presence of pancreatitis. Referrals were all due to the presence of hypertriglyceridemia defined as fasting triglycerides $>6 \mathrm{mmol} / \mathrm{L}$. Selection criteria to undergo genetic screening were fasting triglycerides $>10 \mathrm{mmol} / \mathrm{L}$ and presence of at least one episode of pancreatitis in the absence of secondary risk factors for hypertriglyceridemia (i.e., alcohol use, metabolic syndrome, diabetes mellitus, partial lypodystrophy), presence of consanguinity in the family. All subjects gave informed consent to deoxyribonucleic acid (DNA) analyses and publication.

\section{DNA isolation and sequencing}

Individual exons with flanking intron sequences of the $L P L$ gene were amplified from DNA extracted from ethylenediaminetetraacetic acid-containing blood or saliva using DNeasy Blood kit (Qiagen, Hilden, Germany) and Puregene Buccal Cell Core kit (Qiagen) respectively, according to the manufacturer's instructions. The primers and conditions for thermal cycling are available on request. The PCR products were purified using ExoSAP-IT (USB Corporation, Cleveland, $\mathrm{OH}$ ) according to the manufacturer's instructions. Version 3.1 of the BigDye terminator cycle-sequencing kit (Applied Biosystems, Foster City, CA) was used for the sequencing reactions according to the manufacturer's instructions. The sequencing products were run on a Genetic Analyzer 3730 (Applied Biosystems) and analyzed using Secscape, version 2.5 software (Applied Biosystems).

\section{Site-direct mutagenesis, cloning, and transfection}

Wild type $L P L$ cDNA and c.765_766delAG $L P L$ cDNA were synthesized and cloned in pcDNA3.1 vector with a V5 epitope tag at the C-terminus by GeneArt Gene Synthesis (Thermo Fisher Scientific, Rockford, IL, USA). Single base-pair change from thymine to guanine at nucleotide 1211, resulting into a methionine to arginine substitution (p.M404 R), was introduced by site-directed mutagenesis, to obtain the LPL p.M404 R mutation (primer forward: TTG GAG AAC TAC TCA GGT TGA AGC TCA AAT and primer reverse: ATT TGA GCT TCA ACC TGA GTA GTT CTC CAA). A detailed protocol for mutagenesis is available on request. The presence of the $L P L$ mutation and fidelity of each construct were confirmed by DNA sequencing.

HEK293 cells were cultured in minimum essential media containing 10\% FBS (Fetal Bovine Serum). Expression plasmids (30 $\mu \mathrm{g} / \mathrm{T}-75$ flask) containing the human wild type $L P L$, c.765_766delAG $L P L$, or c.1211 T > G $L P L$, were used to transfect HEK293 cells using TurboFect (Thermo Fisher Scientific) reagent according to the manufacturer's protocol. After $48 \mathrm{~h}$, cells and media were collected. Cells were lysed in M-PER (Mammalian Protein Extraction Reagent, Thermo Fisher Scientific) containing complete protease inhibitor cocktail (Sigma-Aldrich, Saint Louis, Missouri) and analyzed by western blotting. Media were concentrated 10 times by VIVASPIN tubes (Sartorius Stedim Biotech, Germany) and used for LPL activity measurements and protein detection analysis by western blot analysis.

\section{Post-heparin plasma samples}

After overnight fasting, a pre-heparin blood sample was drawn followed by an intravenously bolus injection of heparin (60 IU/kg body weight). After $10 \mathrm{~min}$, a postheparin blood was collected from the contralateral arm. The blood samples were centrifuged at $3000 \mathrm{rpm}$ at $4{ }^{\circ} \mathrm{C}$ for $10 \mathrm{~min}$ to obtain pre-heparin and post-heparin plasma samples (supernatant). The supernatants were stored at $-80^{\circ} \mathrm{C}$ until analyzed.

\section{LPL enzymatic activity}

LPL activity in pre-heparin and post-heparin plasma samples and in media fractions of HEK293 cells overexpressing LPL wild type and the two mutations was measured as previously described. ${ }^{27}$ Briefly, $7.5 \mu \mathrm{L}$ of each plasma sample was mixed with $42.5 \mu \mathrm{L}$ of $0.2-\mathrm{M}$ Tris $\mathrm{HCl}$ buffer ( $\mathrm{pH}$ 8.0). The diluted plasma samples and $50 \mu \mathrm{L}$ of each concentrated medium sample were incubated for 15 minutes at $37^{\circ} \mathrm{C}$ with a radiolabeled substrate $\left[9,10-{ }^{3} \mathrm{H}(\mathrm{N})\right]$-triolein (Perkin Elmer, Waltman, MA), cold triolein, and phosphatidylcholine (Sigma-Aldrich, St Louis, $\mathrm{MO}$ ), heat-inactivated fetal calf serum and bovine serum albumin in presence or absence of $1-\mathrm{M} \mathrm{NaCl}$.

Lipids were extracted by the addition of heptane/ chloroform/methanol (1:1.25:1.41). Samples were centrifuged at $3000 \mathrm{~g}$ for $15 \mathrm{~min}$. The amount of $\left[{ }^{3} \mathrm{H}\right]$-oleic acid released was measured in the upper (aqueous) phase by scintillation counting. Mouse (C57BL/6) postheparin plasma was used as a positive control, whereas $1-\mathrm{M} \mathrm{NaCl}$ was used for LPL specificity.

\section{Immunoblotting}

Pre-heparin and post-heparin plasma samples were diluted 1:50 in 0.5-M Tris- $\mathrm{HCl}(\mathrm{pH} 7)$. The diluted plasma samples, cell lysates, and concentrated media samples were mixed with Laemmli buffer and boiled for 5 min at $95^{\circ} \mathrm{C}$. Proteins were size-separated by SDS-PAGE (10\% acrylamide gel, $200 \mathrm{~V}, 45 \mathrm{~min}$ ) and transferred onto a nitrocellulose membrane (400 mA, $60 \mathrm{~min})$. Membranes were incubated overnight with primary antibodies, washed 2 times for 5 minutes with $0.2 \%$ tris-buffered saline Tween, incubated 1 hour with HRP-conjugated secondary antibodies and washed 3 times for 10 minutes with $0.2 \%$ tris-buffered saline Tween. After 5-minute incubation with chemiluminescent HRP substrate (Millipore Corporation, Billerica, USA), bands were visualized by Chemidoc XRS System (Biorad, Hercules, CA) and Image Lab Software (Biorad).

The following antibodies were used: mouse anti-LPL (Sigma-Aldrich), rabbit anti-HTGL (Hepatic Triglyceride Lipase) (Sigma-Aldrich), mouse anti-APOA1 (AbD 
Serotec, Oxford, UK), mouse anti-V5 (Invitrogen), rabbit anti-Calnexin (Abcam), and mouse anti-Albumin (SigmaAldrich).

\section{Results}

\section{Clinical cases}

A total of three individuals referred to the Lipid Clinic at Sahlgrenska University Hospital in Gothenburg for the presence of hyperlipidemia were screened for the presence of mutations in the $L P L$ gene. The criteria for genetic screening of these patients were fasting triglycerides $>10 \mathrm{mmol} / \mathrm{dL}$, presence of at least one episode of acute pancreatitis requiring hospitalization and of consanguinity in the family (see family tree in Fig. 1).

These conditions must have occurred in the absence of present or past history of excess in alcohol consumption, obesity, and metabolic syndrome (see Table 1 for clinical characteristics of the patients). All probands were from Middle East (Iran and Syria), and DNA or medical records from family members were not available.

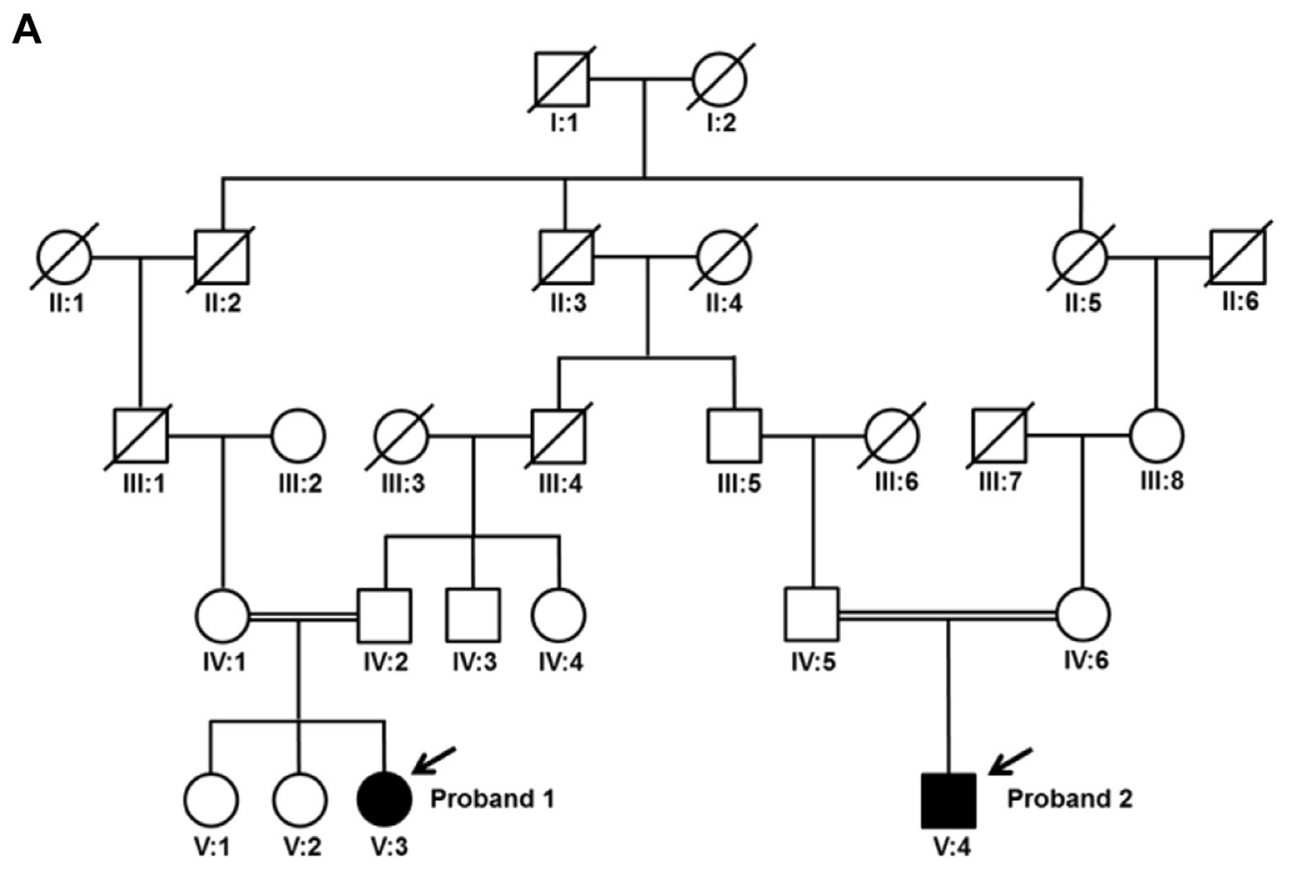

B

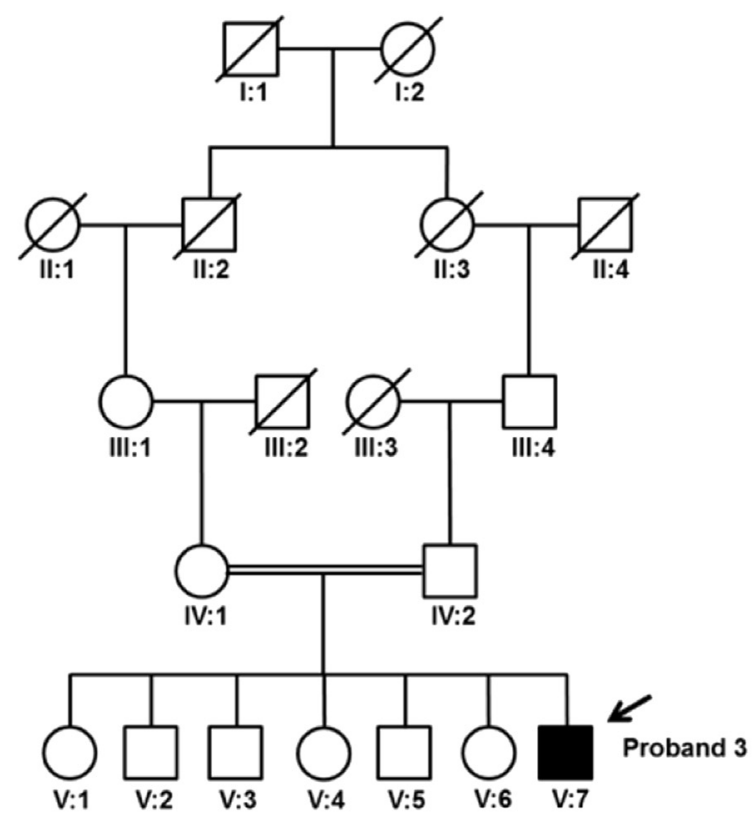

Figure 1 Pedigree of the families. (A) Pedigree of the family with mutation p.G256TfsX26 and (B) with mutation p.M404 R in $L P L$ gene displaying the structure of the second-cousin consanguineous matings. Squares and circles represent male and female family members, respectively, and filled symbols denote affected individuals with homozygous mutations. 
Table 1 Clinical, anthropometric, and lipoprotein profile of the individuals screened for $L P L$ mutations

\begin{tabular}{|c|c|c|c|}
\hline Variable & Proband 1 & Proband 2 & Proband 3 \\
\hline Age & 19 & 32 & 28 \\
\hline Gender & $M$ & $\mathrm{~F}$ & $M$ \\
\hline BMI $\left(\mathrm{Kg} / \mathrm{m}^{2}\right)$ & 24.7 & 15.6 & 27.7 \\
\hline Alcohol intake & No & No & No \\
\hline Diabetes & No & No & No \\
\hline Triglycerides (mmol/L) & $60.7 \pm 7$ & $31.7 \pm 7.8$ & $45 \pm 26.9$ \\
\hline Pancreatitis (yes/no) & Yes & Yes & Yes \\
\hline Number of Pancreatisis & 3 & $>10$ & 1 \\
\hline Cholesterol (mmol/L) & 9.3 & 4.1 & 4.1 \\
\hline HDL-cholesterol (mmol/L) & 0.5 & 0.2 & 1 \\
\hline LDL-cholesterol (mmol/L) & 0.7 & 0.24 & 0.6 \\
\hline
\end{tabular}

BMI, body mass index; HDL, high-density lipoprotein; LDL, lowdensity lipoprotein.

\section{Sequencing of the LPL gene}

Genetic screening in the $L P L$ gene was performed by direct Sanger sequencing. In proband 1 and 2, we found a two base pair deletion (c.765_766delAG; Fig. 2A) resulting in a frame-shift leading to a premature stop codon at position 282 (p.Gly256Thrfs*26). Both probands were homozygous for this mutation. Proband 3 was homozygous for nucleotide substitution (c.1211 T > G; Fig. 2B) resulting into a missense mutation (methionine to arginine substitution at position 404 of the protein, p.M404 R).

\section{LPL activity, synthesis, and secretion in HEK293 cells}

To understand the molecular mechanism underlying hypertriglyceridemia by the novel mutations identified, we cloned the wild type $L P L$ cDNA and the p.G256TfsX26 mutant in a pcDNA3.1 vector and performed mutagenesis in situ on the wild type gene to obtain the p.M404 R mutant. A V5 tag was added at the C-terminus of the protein. Next, HEK293 cells were transiently transfected with these constructs, and the presence of LPL was examined in the cell lysates and media (Fig. 3A and B). HEK293 cells transfected with the mutation p.G256TfsX26 produced about $80 \%$ less protein than cells transfected with the wild-type $L P L$ cDNA. The cells transfected with the p.M404 R mutation showed virtually no protein in the cell lysate (Fig. 3A). Consistently, in the media, LPL was not detected for the mutation p.G256TfsX26 and reduced by $80 \%$ for the mutation p.M404 R (Fig. 3B).

Next, we examined LPL activity in concentrated media from these cells overexpressing the p.G256TfsX26 and the p.M404 R LPL mutants. No LPL activity was detected in the media of cells transfected with either of the two mutant plasmids (Fig. 4).
A

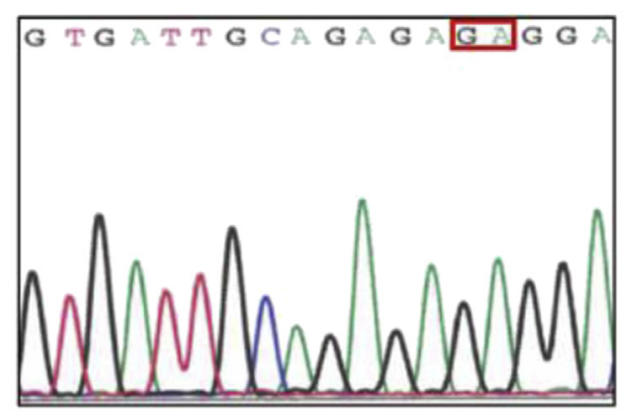

Homozygous c.765_766delAG

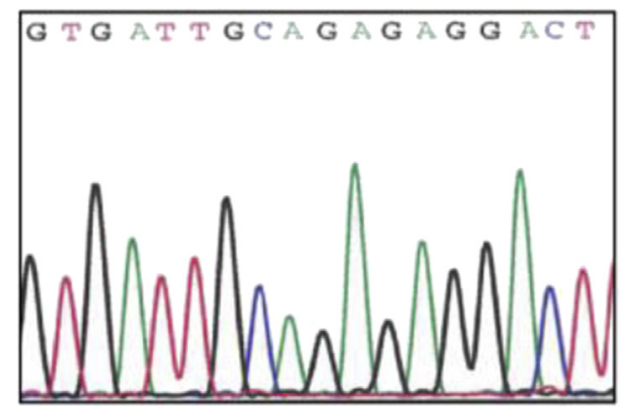

B

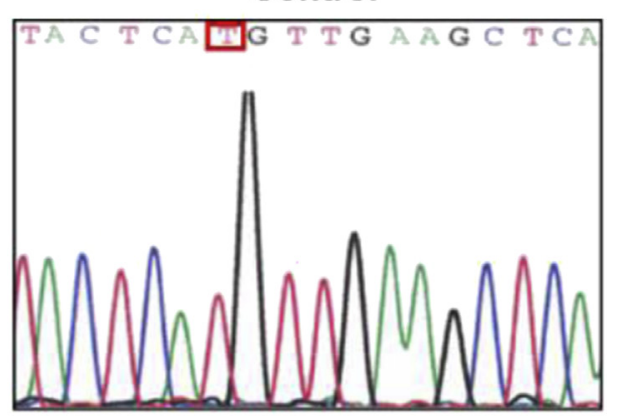

Homozygous c.1211 T>G

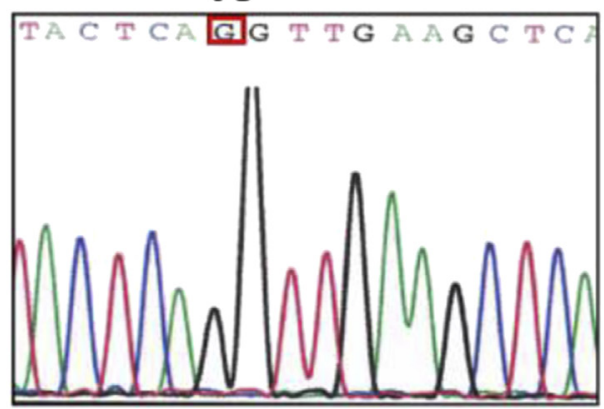

Figure 2 Sequence analysis of the $L P L$ mutations. (A) Segments of genomic DNA sequences of the proband 1 and 2 showing nucleotides c.765_766, which are deleted on both alleles in the affected subjects; deleted nucleotides are shown in the red box in the sequence from the control subject. (B) Segments of genomic DNA sequences of the proband 3 showing mutated nucleotide c.1211 $\mathrm{T}>\mathrm{G}$ in the red box. (Color version of figure is available online.) 

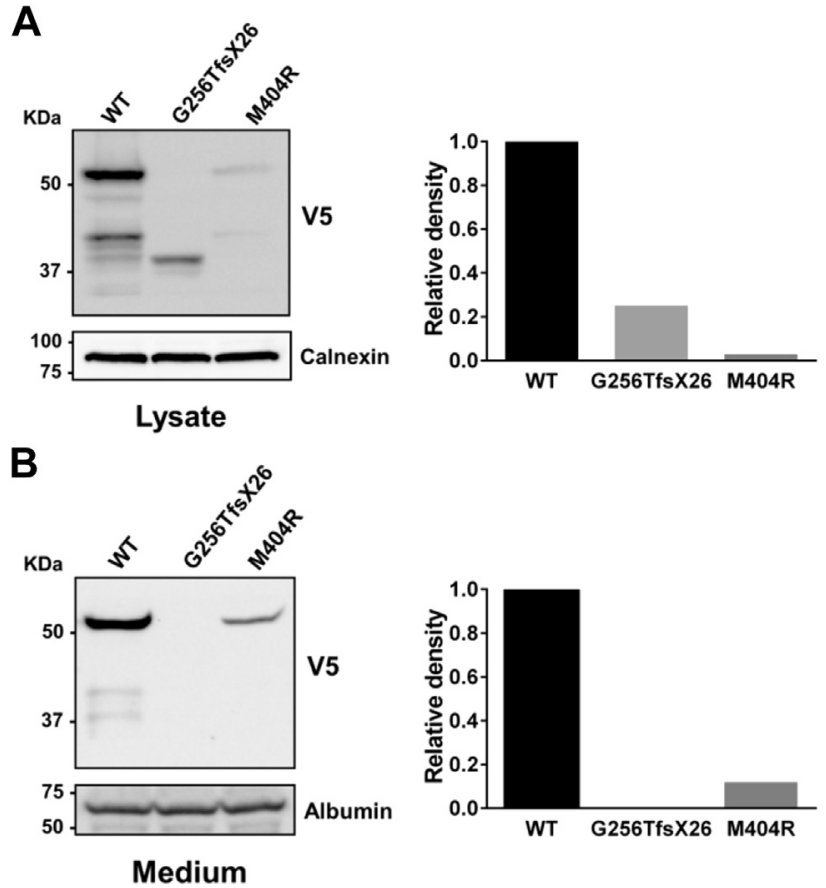

Figure 3 In HEK293 cells transiently transfected, p.G256TfsX26 LPL mutation is less produced and not secreted, whereas p.M404 R LPL is less produced and secreted. (A) Western blotting showing levels of LPL-V5 tagged in the cell lysates of HEK293 cells transfected with wild type, p.G256TfsX26, and p.M404 R LPL; calnexin was used as loading control. (B) Western blotting showing levels of LPL-V5 tagged in the cell media of HEK293 cells transfected with wild type, p.G256TfsX26, and p.M404 R LPL; albumin was used as loading control.

\section{LPL activity and circulating LPL levels}

Pre-heparin and post-heparin plasma samples were collected from patients homozygous for the p.G256TfsX26 or the p.M404 R for LPL activity measurement. In the postheparin plasma of the p.G256TfsX26 homozygotes, no

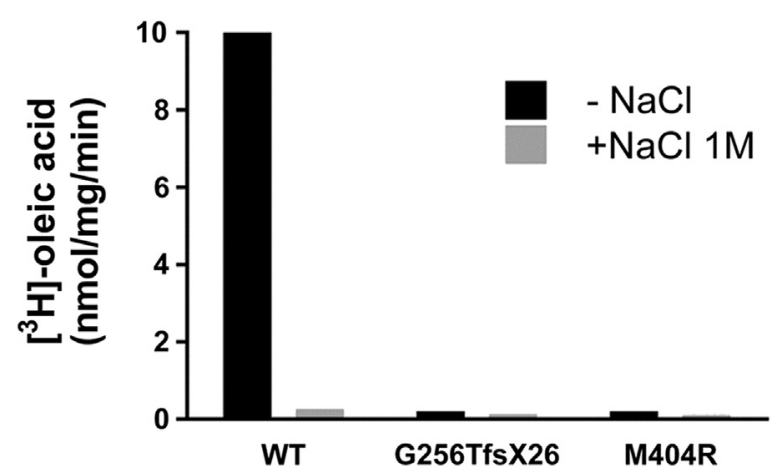

Figure 4 LPL activity is absent in the cell media of HEK293 cells transfected with p.G256TfsX26 and p.M404 R LPL. LPL induced release of radiolabeled oleic acid from triolein was measured in cell media of HEK293 transiently transfected with wild type, p.G256TfsX26, and p.M404 R LPL. Wild type LPL medium was used as a positive control. Sodium chloride $1 \mathrm{M}(\mathrm{NaCl})$ was used to inhibit specifically LPL activity.

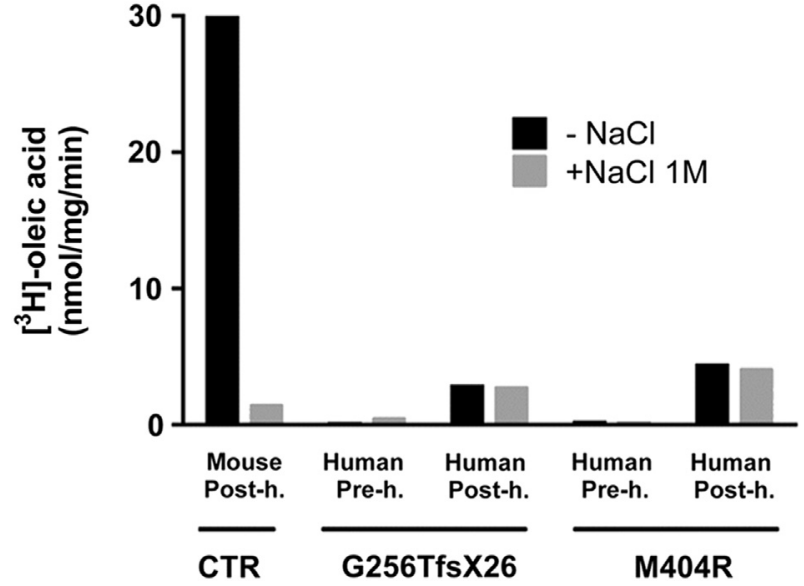

Figure 5 LPL activity is absent in pre-heparin and post-heparin plasma from individuals with p.G256TfsX26 or p.M404 R mutations. LPL induced release of radiolabeled oleic acid from triolein was measured in pre-heparin and post-heparin plasma from subjects homozygous for the two base pair deletion frameshift mutation (p.G256TfsX26) and the missense mutation (p.M404 R). Mouse post-heparin plasma was used as a positive control for increased LPL activity in post-heparin plasma. Sodium chloride $1 \mathrm{M}(\mathrm{NaCl})$ was used to inhibit specifically LPL activity. Pre-h: pre-heparin; Post-h: post-heparin; $\mathrm{NaCl}$ : sodium chloride.

release of oleic acid from triolein was observed indicating no LPL activity (Fig. 5). In the post-heparin plasma of the subject homozygous for the p.M404 R mutation, a fairly small amount of oleic acid release was detected (Fig. 5). This release was not inhibited by sodium chloride suggesting that it was due to HTGL. As no lipase activity was detected in the plasma of patients, we examined protein levels in the serum.

LPL protein was absent in the pre-heparin and post-heparin plasma of the subject homozygous for the p.G256TfsX26 (Fig. 6A), whereas it was present at a very low level in the pre-heparin and post-heparin plasma of the p.M404 R
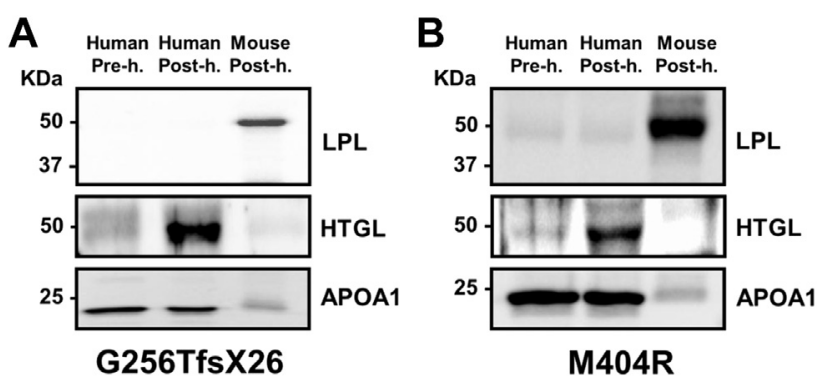

Figure 6 Circulating LPL levels in pre-heparin and post-heparin plasma from subjects with p.G256TfsX26 or p.M404 R mutation. (A) Western blotting showing circulating levels of LPL and HTGL in pre-heparin and post-heparin plasma samples from a subject carrying the p.G256TfsX26 mutation and (B) the p.M404 R mutation. Mouse post-heparin plasma was used as a positive control (mouse and human LPL amino acidic sequences show $>90 \%$ homology). Anti-human APOA1 antibody was used as a loading control. Pre-h, preheparin; Post-h, postheparin; KDa, kilodalton; LPL, lipoprotein lipase; HTGL, hepatic triglyceride lipase; APOA1, apolipoprotein A1. 
homozygotes (Fig. 6B). HTGL was present at low level in both individuals in the pre-heparin and increased in the post-heparin plasma of both patients.

\section{Discussion}

Type I hyperlipoproteinemia is a rare autosomal recessive disorder of lipoprotein metabolism caused by mutations in the $L P L$ gene. ${ }^{19,28}$ In this study, we have identified two novel mutations in the $L P L$ gene causing type I hyperlipoproteinemia.

In our genetic screening, we obtained a high success rate in detecting mutation in the $L P L$ gene. This may be due to the stringent criteria that we used to identify probands. Indeed the inclusion of only individuals with the presence of at least one pancreatitis episode in the absence of metabolic and alcohol-related cause of hypertriglyceridemia restricted the number of individuals screened. It is also worth noting that all three of our probands had a consanguineous marriage explaining the presence of the disease in a homozygous state.

Gothenburg area has approximately 600,000 inhabitants. The prevalence of LPL deficiency is estimated to be one in one million. Since the early 1970s, Sweden has had a large migratory flux from Middle East, ${ }^{29}$ the region where the three probands came from. In this region, consanguineous marriage is relatively common. ${ }^{30}$ We identified two mutations (p.G256TfsX26 and the p.M404 R) that to the best of our knowledge have not been previously reported. These mutations are not annotated in the Exome Aggregate Consortium (ExAC) database, which comprises more than 60,000 individuals. To date, more than 220 pathogenic mutations have been identified ( $70 \%$ missense, $10 \%$ nonsense, $18 \%$ rearrangements, and $2 \%$ unknown mutations). ${ }^{31,32}$ In silico analysis using PolyPhen2 and SIFT prediction programs indicated that mutation M404 $\mathrm{R}$ was probably damaging.

To understand the molecular mechanism underlying our genetic findings, we showed that HEK293 cells transfected with a plasmid encoding the mutation p.G256TfsX26 produced about $80 \%$ less protein than cells transfected with the wild type $L P L$, whereas the cells transfected with the p.M404 $\mathrm{R}$ mutation showed even much lower abundance of the protein. In the media of the transfected cells, the LPL protein was not detected for the mutation p.G256Tfs X26 and reduced by $80 \%$ for the mutation p.M404 R. No LPL activity was detected in concentrated media from these cells transfected with both the mutations. Consistently, no lipase activity was detected in the pre-heparin or post-heparin plasma of patients, and LPL was absent from post-heparin plasma of the p.G256TfsX26 homozygote but was present at a very low level in the pre-heparin and post-heparin plasma of the p.M404 R homozygotes. Taken together, these data suggest that both the mutations severely affect the protein synthesis/secretion and consequently the enzymatic activity of LPL protein, explaining the severe phenotype in the patients carrying these mutations.

In particular, we speculate that the LPL p.G256TfsX26 causes mRNA decay. ${ }^{33}$

Regarding the p.M404 R mutation, LPL acts as a homodimeric enzyme, and each monomer consisting of a larger N-terminal catalytic domain and a smaller C-terminal region that plays a key role in binding triglyceride substrates. ${ }^{34-37}$ In 2011, Voss et al. have shown that LPL's $\mathrm{C}$ terminus plays an important role in LPL-GPIHBP1 interactions. In fact, a pair of missense mutations in LPL's C-terminal domain, p.C418Y and p.E421 K, abolishes LPL's capacity to bind to GPIHBP $1{ }^{38}$ This finding could explain why the administration of heparin did not change levels of the LPL in proband 3. Furthermore, other two mutations in the LPL's C-terminal, the E410 V and G412 R mutation, were associated with very low levels of LPL mass and activity in the post-heparin plasma. ${ }^{39,40}$ However, the mechanism on the basis of these effects is not clear, and we hypothesize that LPL p.M404 R is degraded within cells. Moreover, in our in vitro experiments, we show no LPL activity despite residual secretion indicating a loss of the enzymatic activity in this mutant.

In conclusion, we have described two novel mutations of the $L P L$ gene causing Type I hyperlipoproteinemia by disrupting LPL synthesis and enzymatic activity.

\section{Acknowledgments}

Authors' contribution: All authors contributed to the manuscript preparation. Drs Romeo, Wiklund, Pingitore, Mancina, Motta, Valenti, Berge, Retterstøl, and Leren interpreted the data. Drs Romeo and Pirazzi performed clinical diagnosis. Drs Romeo and Wiklund designed the study. Drs Pingitore and Lepore performed experiments. Drs Berge and Leren performed genetic analyses.

\section{Financial disclosure}

Dr Romeo has received consulting honorary from Chiesi Farmaceutici Group, Amgen, Sanofi, Novonordisk, and Genzyme. Dr Retterstøl has received consulting honorary from Apotek 1, Abbot, Chiesi, Genzyme, Norwegian Directory of Health, Mills DA, MSD (Norway), Norwegian Medicine Agency, Pfizer, Sanofi.

\section{References}

1. Persson B, Bengtsson-Olivecrona G, Enerbäck S, Olivecrona T, Jörnvall H. Structural features of lipoprotein lipase. Lipase family relationships, binding interactions, non-equivalence of lipase cofactors, vitellogenin similarities and functional subdivision of lipoprotein lipase. Eur J Biochem. 1989;179:39-45.

2. Rader DJ, Jaye M. Endothelial lipase: a new member of the triglyceride lipase gene family. Curr Opin Lipidol. 2000;11:141-147. 
3. Deeb SS, Peng RL. Structure of the human lipoprotein lipase gene. Biochemistry. 1989;28:4131-4135.

4. Winkler FK, D'Arcy A, Hunziker W. Structure of human pancreatic lipase. Nature. 1990;343:771-774.

5. Emmerich J, Beg OU, Peterson J, et al. Human lipoprotein lipase. Analysis of the catalytic triad by site-directed mutagenesis of Ser132, Asp-156, and His-241. J Biol Chem. 1992;267:4161-4165.

6. Sendak RA, Bensadoun A. Identification of a heparin-binding domain in the distal carboxyl-terminal region of lipoprotein lipase by sitedirected mutagenesis. J Lipid Res. 1998;39:1310-1315.

7. Goldberg IJ. Lipoprotein lipase and lipolysis: central roles in lipoprotein metabolism and atherogenesis. J Lipid Res. 1996;37: 693-707.

8. Parthasarathy N, Goldberg IJ, Sivaram P, Mulloy B, Flory DM, Wagner WD. Oligosaccharide sequences of endothelial cell surface heparan sulfate proteoglycan with affinity for lipoprotein lipase. $J$ Biol Chem. 1994;269:22391-22396.

9. Young SG, Zechner R. Biochemistry and pathophysiology of intravascular and intracellular lipolysis. Genes Dev. 2013;27:459-484.

10. Pasalić D, Jurcić Z, Stipancić G, et al. Missense mutation W86R in exon 3 of the lipoprotein lipase gene in a boy with chylomicronemia. Clin Chim Acta. 2004;343:179-184.

11. Kersten S. Physiological regulation of lipoprotein lipase. Biochim Biophys Acta. 2014;1841:919-933.

12. Péterfy M. Lipase maturation factor 1: a lipase chaperone involved in lipid metabolism. Biochim Biophys Acta. 2012;1821:790-794.

13. Berge KE, Retterstøl K, Romeo S, Pirazzi C, Leren TP. Type 1 hyperlipoproteinemia due to a novel deletion of exons 3 and 4 in the GPIHBP1 gene. Atherosclerosis. 2014;234:30-33.

14. Ramasamy I. Update on the molecular biology of dyslipidemias. Clin Chim Acta. 2016;454:143-185.

15. Foubert L, Benlian P, Turpin G. [Lipoprotein lipase: a multifunctional enzyme in lipoprotein metabolism]. Presse Med. 1996;25: 207-210.

16. Murthy V, Julien P, Gagne C. Molecular pathobiology of the human lipoprotein lipase gene. Pharmacol Ther. 1996;70:101-135.

17. Santamarina-Fojo S. The familial chylomicronemia syndrome. Endocrinol Metab Clin North Am. 1998;27:551-567 viii.

18. Beigneux AP, Davies BS, Gin P, et al. Glycosylphosphatidylinositolanchored high-density lipoprotein-binding protein 1 plays a critical role in the lipolytic processing of chylomicrons. Cell Metab. 2007;5: 279-291.

19. Hegele RA, Ginsberg HN, Chapman MJ, et al. The polygenic nature of hypertriglyceridaemia: implications for definition, diagnosis, and management. Lancet Diabetes Endocrinol. 2014;2:655-666.

20. Gaudet D, Méthot J, Kastelein J. Gene therapy for lipoprotein lipase deficiency. Curr Opin Lipidol. 2012;23:310-320.

21. Gaudet D, de Wal J, Tremblay K, et al. Review of the clinical development of alipogene tiparvovec gene therapy for lipoprotein lipase deficiency. Atheroscler Suppl. 2010;11:55-60.

22. Wierzbicki AS, Reynolds TM, Crook MA. Usefulness of Orlistat in the treatment of severe hypertriglyceridemia. Am J Cardiol. 2002; 89:229-231.
23. Tzotzas T, Krassas GE, Bruckert E. Administration of orlistat in a patient with familial hyperchylomicronemia. Atherosclerosis. 2002;165: 185-186.

24. Melchiorri D, Pani L, Gasparini P, et al. Regulatory evaluation of Glybera in Europe - two committees, one mission. Nat Rev Drug Discov. 2013;12:719.

25. Büning $\mathrm{H}$. Gene therapy enters the pharma market: the short story of a long journey. EMBO Mol Med. 2013;5:1-3.

26. Gaudet D, Méthot J, Déry S, et al. Efficacy and long-term safety of alipogene tiparvovec (AAV1-LPLS447X) gene therapy for lipoprotein lipase deficiency: an open-label trial. Gene Ther. 2013;20:361-369.

27. Nilsson-Ehle P, Schotz MC. A stable, radioactive substrate emulsion for assay of lipoprotein lipase. J Lipid Res. 1976;17:536-541.

28. Fellin R, Baggio G, Poli A, et al. Familial lipoprotein lipase and apolipoprotein C-II deficiency. Lipoprotein and apoprotein analysis, adipose tissue and hepatic lipoprotein lipase levels in seven patients and their first degree relatives. Atherosclerosis. 1983;49:55-68.

29. Westin C. Sweden: restrictive immigration policy and multiculturalism. 2006 Available at: http://www.migrationpolicy.org/article/swedenrestrictive-immigration-policy-and-multiculturalism/; 2006 The online journal of the migration policy institute. Accessed December 1, 2015.

30. Al-Herz W, Al-Mousa H. Combined immunodeficiency: the Middle East experience. J Allergy Clin Immunol. 2013;131:658-660.

31. Gilbert B, Rouis M, Griglio S, de Lumley L, Laplaud P. Lipoprotein lipase (LPL) deficiency: a new patient homozygote for the preponderant mutation Gly 188Glu in the human LPL gene and review of reported mutations: $75 \%$ are clustered in exons 5 and 6. Ann Genet. 2001;44:25-32.

32. Brunzell JD. Familial lipoprotein lipase deficiency. In: A. M, Pagon RA, Ardinger HH, et al., editors. GeneReviews ${ }^{\circledR}$ [Internet]. Seattle (WA): University of Washington, Seattle, 1993-2015., and O. u. A. 24]. editors; 2014.

33. Chang YF, Imam JS, Wilkinson MF. The nonsense-mediated decay RNA surveillance pathway. Апnи Rev Biochem. 2007;76:51-74.

34. Wong H, Davis RC, Thuren T, et al. Lipoprotein lipase domain function. J Biol Chem. 1994;269:10319-10323.

35. Wong H, Schotz MC. The lipase gene family. J Lipid Res. 2002;43: 993-999.

36. Kobayashi Y, Nakajima T, Inoue I. Molecular modeling of the dimeric structure of human lipoprotein lipase and functional studies of the carboxyl-terminal domain. Eur J Biochem. 2002;269:4701-4710.

37. Zhang L, Lookene A, Wu G, Olivecrona G. Calcium triggers folding of lipoprotein lipase into active dimers. J Biol Chem. 2005;280: 42580-42591.

38. Voss CV, Davies BS, Tat S, et al. Mutations in lipoprotein lipase that block binding to the endothelial cell transporter GPIHBP1. Proc Natl Acad Sci U S A. 2011;108:7980-7984.

39. Previato L, Guardamagna O, Dugi KA, et al. A novel missense mutation in the C-terminal domain of lipoprotein lipase (Glu410->Val) leads to enzyme inactivation and familial chylomicronemia. $J$ Lipid Res. 1994;35:1552-1560.

40. Ginzinger DG, Lewis ME, Ma Y, Jones BR, Liu G, Jones SD. A mutation in the lipoprotein lipase gene is the molecular basis of chylomicronemia in a colony of domestic cats. J Clin Invest. 1996;97:1257-1266. 